\title{
Along-Dip Segmentation of the Slip Behavior and Rheology of the Copiapó Ridge Subducted in North-Central Chile
}

\section{F. Pastén-Araya ${ }^{1 *}$, B. Potin ${ }^{1}$, K. Azúa ${ }^{1}$, M. Sáez ${ }^{1}$ F. Aden-Antoniów ${ }^{2}, \quad$ S. Ruiz ${ }^{1}$, L. Cabrera $^{3}$, J.P. Ampuero ${ }^{5}$, J.M. Nocquet ${ }^{5}$, L. Rivera ${ }^{6}$ and Z.Duputel ${ }^{4}$}

${ }^{1}$ Departamento de Geofísica, Universidad de Chile, Santiago, Chile.

${ }^{2}$ Department of Earth, Atmospheric and Planetary Sciences, Massachusetts Institute of Technology, Cambridge, MA, USA.

${ }^{3}$ ISTerre Institut des Sciences de la Terre, CNRS, Université Grenoble Alpes, 38058 Grenoble Cedex 9, France.

${ }^{4}$ Observatoire Volcanologique du Piton de la Fournaise, Universite de Paris, Institut de Physique du Globe de Paris, CNRS, F-75005, Paris France.

${ }^{5}$ Université Côte d'Azur. IRD, CNRS, Observatoirede la Côte d'Azur, Géoazur, 250 rue Albert Einstein, Sophia Antipolis, 06560 Valbonne, France.

${ }^{6}$ Université de Strasbourg, CNRS, ITES UMR 7063, Strasbourg F-67084, France.

*Corresponding author: F. Pastén-Araya, fpasten@dgf.uchile.cl

\section{Key Points}

- We identify distinct along-dip segments hosting seismicity, clusters of similar events, non-volcanic tremors and slow slip.

- Low $\mathrm{Vp}$ and $\mathrm{Vs}$ velocities with moderate $\mathrm{Vp} / \mathrm{Vs}$ ratio suggest the presence of fluids in the aseismic zones.

- We propose these marked differences in seismic behavior are due to the subduction of the Copiapó ridge.

\section{Abstract}

We studied the along-dip influence of the Copiapó ridge subduction in the Atacama region, North-Central Chile by building a new seismicity catalog, including similar events and non-volcanic tremors (NVTs). We also obtained a 3-D tomographic model for $\mathrm{P}$ - and $\mathrm{S}$-waves velocity (and the implied $\mathrm{Vp} / \mathrm{Vs}$ ratio). We identify down-dip segmentation involving 4 distinct segments: a locked seismogenic zone hosting ordinary seismicity and clusters of similar events; a transition zone with NVTs and low seismicity; an aseismic zone 
with slow-slip events; and a deep zone with abundant intraslab seismicity. The velocity models show differences among these zones, with low velocity anomalies of $\mathrm{Vp}$ and $\mathrm{Vs}$ coinciding with aseismic slip zones, indicating the possible presence of fluids. Due to the spatial distribution along-strike and along-dip of the aseismic zones, we propose that these differences in seismogenic behavior are generated by subduction of the heterogeneous seamounts associated with the Copiapó ridge.

\section{Plain Language Summary}

Several studies suggest that subduction of large bathymetric features such as seamounts and fracture zones can produce aseismic slip in the subduction zones. We investigate the possible influence of the subduction of the Copiapó ridge in north-central Chile. Our results show down-dip zones with distinct seismic and aseismic behavior. The seismic zones are distinguished by ordinary seismicity and high coupling values, while the aseismic zones are characterized by low coupling values, clusters of similar events, non-volcanic tremor and slow-slip events. In addition, by means of a three-dimensional tomography model, we suggest that fluids are present in the aseismic zones which can help to produce aseismic slip. All these consistent observations exhibit a significant spatial correlation with the Copiapó ridge. Therefore we propose these differences in the seismic behavior are due to the subduction of the Copiapó ridge.

\section{Introduction}

The segmentation and the probable extent of seismic ruptures of subduction earthquakes along-strike and down-dip are still under debate and remain as open questions. Several studies have proposed that the extent of seismic ruptures might be controlled by different factors such as: the presence of fluids and sediment entering the subduction zone (Liu and Zhao, 2018; Baba et al., 2020); differences in the geology of the upper plate (Bassett et al., 2016; Maksymowicz et al., 2018) and the subduction of large bathymetric features in the oceanic crust like seamounts and oceanic ridges (Wang and Bilek, 2011, 2014; Kato et al., 2010; Maksymowicz, 2015). The latter is particularly noteworthy since several megathrust earthquakes have stopped close to bathymetric features, thus leading several studies to suggest that these oceanic features act as seismic barriers along-strike of the megathrust (Contreras-Reyes and Carrizo, 2011; Wang and Bilek, 2011, 2014; Bassett and Watts, 2015a, 2015b; Henstock et al., 2016; Lallemand et al., 2018). In addition, the subduction of these bathymetric features is linked to other seismic observations like seismic swarms, nonvolcanic tremors (NVTs) and slow-slip events (SSEs) (Poli et al., 2017; Nishikawa and Ide, 2018, Nishikawa et al., 2019). Trehu et al. (2012) showed evidence of correlation between seismicity clusters and seamount subduction in the Cascadia subduction zone, while Kodaira et al. (2004) and Kato et al. (2010) established a 
connection between the subduction of an oceanic ridge and the frequent occurrence of SSEs in the Nankai subduction zone. Although the potential influence of bathymetric features on seismic ruptures along-strike has been abundantly discussed in past works, an accurate assessment of their influence at depth remains challenging. In particular, we still need to understand why some regions are more prone to aseismic slip than others.

The Atacama North-Central region of the Chilean margin $\left(26^{\circ}-28.5^{\circ} \mathrm{S}\right)$, where the Copiapó Ridge (CoR) is subducting below the South American margin, is currently characterized by a seismic gap (Ruiz and Madariaga, 2018). The CoR is made of different seamounts of diverse geometries and considerable heights ( $2000 \mathrm{~m} \mathrm{high)} \mathrm{(Figure} \mathrm{1).} \mathrm{The} \mathrm{CoR} \mathrm{subduction} \mathrm{coincides} \mathrm{with} \mathrm{a} \mathrm{zone} \mathrm{of} \mathrm{low} \mathrm{interseismic} \mathrm{coupling,}$ separating two areas of high coupling that could potentially generate large subduction earthquakes (Mw > 8.5) (Klein et al., 2018a). In addition, seismic swarms have been reported in this area in 1973, 1979 and 2006 (Comte et al., 2002; Holtkamp et al., 2011). The latter occurred between April and May 2006 with a total of 180 reported events (Figure 1) (Comte et al, 2006). A SSE in 2014 was detected deeper along the interface, at approximately $50 \mathrm{~km}$ depth (Klein et al., 2018b) with an equivalent magnitude 6.9 (Figure 1). Continuous GPS data of the global network suggest that SSEs recurrently occur every 4-5 years in that area (Klein et al., 2018b).

Large megathrust earthquakes also occurred in the past, the largest one in 1922 (Mw 8.5-8.8), and several moderate earthquakes have occurred more frequently e.g. 1796, 1918, 1983 (Beck et al., 1998; Ruiz and Madariaga, 2018; Kanamori et al., 2019). The last event, with Mw 6.9, happened on September 1, 2020 and was part of a remarkable seismic and a-seismic sequence (Klein et al., 2021) (Figure 1). Most ruptures of moderate magnitude earthquakes $(<7.5)$ that initiated north of the CoR stopped at the CoR, although the large megathrust earthquake of 1922 appears to ruptured through it.

We deployed a temporary seismological network to study the seismicity associated with the CoR and eventually to understand how it might control the along-dip seismic behavior of the plate interface. We conducted an effective search for similar events and NVTs, clues for potential aseismic slip. Using a nonlinear tomography method, we built 3-D P- and S-wave velocity models and a Vp/Vs ratio model to investigate the rheology and the possible presence of fluids along the plate interface.

\section{Data, Methods and Results}

Seismic monitoring is performed by 5 permanent stations of the Centro Sismológico Nacional (CSN) within $200 \mathrm{~km}$ around the study area. 3 semi-permanent stations of the University of Strasbourg also monitor the region since 2019 (Zigone et al., 2019). In order to increase the detection capability for this study, we installed 10 temporary broad-band stations, in 2 different settings, during 4 months each (Figure 1). The first phase of acquisition ran from June $24^{\text {th }}$ to October $8^{\text {th }}$ of 2019 and the second phase from October $9^{\text {th }}$ of 2019 to January $17^{\text {th }}$ of 2020 . In total, we acquired data for 8 months, with a total of 28 stations of which 8 were permanent during the entire experiment. 


\subsection{Seismic Catalog}

127 During the 8 months of data acquisition, the network detected tens of thousands of local and regional events. 128 In order to build a robust catalog, we implemented both manual and automatic phase-arrival picking. For the 129 manual picking, earthquake detection was performed by a multistage approach. Firstly, we roughly identified 130 potential events by a conservative STA/LTA detection method on each station. Secondly, we filtered out the 131 hundreds of very-low magnitude events and most of the outliers by considering only the potential wave132 arrivals observed on for at least 5 stations. Finally, we gathered these potential-arrivals into potential-events 133 and manually inspected them. We selected only events for which at least 1 station had an arrival time 134 difference between P- and S-wave smaller than 25 seconds, limiting the study area to approximately $200 \mathrm{~km}$ 135 radius around the network. Picking was performed using Seisan (Havskov and Ottemöller, 2008). Due to the quality of the records obtained, we were able to manually picked a portion of the data between the months of August-September of the first phase and November-January of the second phase. We obtained 1,477 events made of 16,745 P- and 14,653 S-wave arrival times.

139 To complete this catalog, we trained a neural network algorithm with the manual catalog to detect and pick arrival times. This algorithm was able to detect and pick accurately well identified events. To filter outliers, very small and quarry blasts events, we selected only events detected by at least 5 stations, with at least 7 arrival-times of which at least 1 corresponded to a P-wave and 1 to an S-wave. We located the resulting catalog to geographically select local events and uncover large arrival-time residuals potentially corresponding to misidentified data. We use this method for 35 days between September-October of the first phase and 45 days between November-December of the second phase, completing the rest of the registration that could not be done manually. This automatic approach identified 2,483 events with 18,914 P- and 18,308 S-wave arrival-times. Therefore, our final catalog consists of 3,960 events between August 2019 and January 2020, with 35,659 P- and 32,961 S-wave arrival-times, with local magnitudes between 0.3 and 4.6, and the completeness magnitude of 1.45 (See catalogs in supplementary material).

In figure $2 \mathrm{~b}$, we represent a projection of the seismicity on the profile $A-A^{\prime}$ identified on figure $2 \mathrm{a}$. The seismicity corresponds to all events between the two dashed black lines of figure 2a. Three seismicity planes or double seismic zone can be recognized. This pattern has been observed in other regions along the Chilean margin (Comte et al., 1999; Marot et al., 2013; Bloch et al., 2014). The upper plane correspond to interplate seismicity and is bounded between 20 and $32 \mathrm{~km}$ depth. The intermediate plane, between 32 and $80 \mathrm{~km}$ depth, is apparently located in the oceanic crust (blue segmented line in Figure 2b). The lower plane (red segmented line in Figure 2b) is located in the upper oceanic mantle and presents most of the seismicity between 45 and $60 \mathrm{~km}$ depth, decaying towards 60 and $80 \mathrm{~km}$ depth, and increasing again between 80 and $110 \mathrm{~km}$ depth. The two deepest planes tend to merge between 100 and $120 \mathrm{~km}$ depth. The seismicity in the upper plate is scarce, with a marked eastward seismicity limit at $69.5^{\circ} \mathrm{S}$. The clusters observed between 0 and $5 \mathrm{~km}$ depth correspond to mining activity (Figure $2 \mathrm{~b}$ ). 


\subsection{Clusters of Similar Events}

163 We investigated the possible presence of repeating earthquakes or similar events which could indicate if aseismic slip takes place, especially on the interface and near the region of the recurrent deep slow-slip observed by Klein et al (2018b). From the manually picked catalog we selected the events located at a depth of $60 \mathrm{~km}$ or above for a matched-filter search (Gibbons and Ringdal, 2006). This selection resulted in 908 templates with S-P times ranging from 6 to 25 seconds. By doing so the P- and S- waves won't be contained in the same window (e.g. Igarashi et al., 2020) however the moveouts, the different arrival times with respect to the first arrival across the network, will be constant in the matched-filter search. This allow us limit the decrease of similarity by using to large template waveforms while keeping the information of the S-P times intact.

To build the templates, we cut the waveform 1 second before the P-wave arrival on the vertical components and 4 seconds after the $\mathrm{S}$-wave arrival on the two horizontal components to limit the overlap of the different seismic arrivals. Due to the magnitudes in our catalog, we conducted the scan using three components at each station, on data filtered between 2 to $8 \mathrm{~Hz}$ (Uchida and Matsuzawa, 2013) and 1 to $15 \mathrm{~Hz}$ (Uchida, 2019). P- and S-waves correlations were performed on the vertical and horizontal components respectively. We found repeating events with a frequency-bands between 2 and $8 \mathrm{~Hz}$, in more than three stations with a correlation coefficient greater than or equal to 0.95 (Figure 2c), however we did not find any in frecuencybands between 1 to $15 \mathrm{~Hz}$. Due to the difference in these results, we decided to define these events as clusters of similar events. We obtained a total of 27 similar events (Table S1) for the period June 24 $4^{\text {th }}, 2019$, to January $17^{\text {th }}, 2020.12$ of these detections seem to be related to mining activity, with local magnitudes < located around $27.5^{\circ} \mathrm{S}$ of latitude, at a depth of 18 and $29 \mathrm{~km}$ along the interface with one pair at a depth of $51 \mathrm{~km}$, with a local magnitudes between 1.3 and 2.5 (Figures $2 \mathrm{~b}$ ). These similar events seem to be aligned with the CoR, potentially co-located with the deep SSE (Figures 1 and 2a) and in less coupled zones (Figure S1).

\subsection{Non-Volcanic Tremor Search}

189 To detect non-volcanic tremors (NVTs) activity, we use the envelope correlation method (Ide, 2010, 2012).

190 Hypocenters of tremors are determined as follow: velocity data are band-pass filtered between 1 and $10 \mathrm{~Hz}$.

191 Filtered traces are squared, low-pass filtered at $0.1 \mathrm{~Hz}$ and resampled at $1 \mathrm{~Hz}$. The distinct trace obtained is 192 called the envelope data (Figure S2). For all stations separated by less than $100 \mathrm{~km}$, the envelopes of 193 horizontal components are cross correlated using a 5-minute time window with a 150s overlap. Following 194 Saéz et al. (2019), a tremor is identified if the cross-correlation coefficient is greater than 0.6 for more than 195 five pairs of stations. 
196 Because of the elevated seismicity rate in the area, many local distant earthquakes were detected. We carried 197 out a visual inspection to eliminate false detections. Figure 2a shows the spatial distribution of NVTs activity 198 after visual inspection (Figures S3 to S8). This NVTs activity was identified uniquely on September $20^{\text {th }}$, 1992019 (Table S2), with a clear lack of P- and S-wave arrivals (Figure 2d). The NVTs activity is located 200 between $27^{\circ} \mathrm{S}-27.5^{\circ} \mathrm{S}$ and $70.5^{\circ} \mathrm{W}-71^{\circ} \mathrm{W}$, with dispersion in depth (Figures S9 to S20), however, most of 201 them are concentrated towards the downdip or transition zone (Figures 2a and 2b), which exhibits low 202 coupling values (Figure S1). The NVTs activity is updip of the SSE slip and, as the clusters of similar events, 203 present a spatial correlation with the CoR subduction (Figure 2a).

\subsection{3-D Tomography Model}

To build a 3-D tomographic model we use the INSIGHT code (Potin et al., 2016). The model consists of a set of $\mathrm{Vp}, \mathrm{Vs}$ and $\mathrm{Vp} / \mathrm{Vs}$ values at each node of a regularly spaced three-dimensional grid constituting the inversion grid. The inversion was carried out using a nonlinear minimization approach based on a stochastic description of the data and the model (see Text 1 in supplementary material for more details). Using the arrival times from our catalog, we build local $\mathrm{Vp}$ and $\mathrm{Vs}$ velocity models and $\mathrm{Vp} / \mathrm{Vs}$ ratio of the region from $26.5^{\circ} \mathrm{S}$ to $28^{\circ} \mathrm{S}$ and from $69^{\circ} \mathrm{W}$ to $72^{\circ} \mathrm{W}$. These models were derived from the arrival times of 35,659 P-waves and 32,961 S-waves corresponding to 3,960 events on an inversion grid consisting of $1,175,878$ cells with a longitudinal, latitudinal, and vertical resolution size of $3 \mathrm{~km}, 3 \mathrm{~km}$ and $1.5 \mathrm{~km}$, respectively (See Figure S21 and S22 for initial model used to make the Vp and Vs models and S23 to travel-time residues in the inversion).

To visualize the velocity variations along-dip, we extracted a cross-section along profile A-A' (blue segmented lines in Figure 2a). Figure 3 shows the results of relative Vp and Vs velocities and Vp/Vs ratio. The upper plate shows higher Vp and Vs values towards shallow depths $(0-20 \mathrm{~km})$ and intermediate values for deeper zones $(20-35 \mathrm{~km})$, while the $\mathrm{Vp} / \mathrm{Vs}$ ratio vary between 1.68 and 1.76 . In the oceanic crust, at depths between 20 and $40 \mathrm{~km}$ depths, $\mathrm{Vp}$ and $\mathrm{Vs}$ values are moderate to low, with $\mathrm{Vp} / \mathrm{Vs}$ ratio between 1.78 and 1.82. Between 40 and $60 \mathrm{~km}$ depths, a marked anomaly is observed with remarkably low Vp and Vs values and $\mathrm{Vp} / \mathrm{Vs}$ ratio between 1.74 and 1.76 . Between 60 and $110 \mathrm{~km}$ depth, $\mathrm{Vp}$ and Vs values return to intermediate ranges and the $\mathrm{Vp} / \mathrm{Vs}$ ratio increases from 1.78 to 1.83 . Finally, in the upper oceanic mantle, $\mathrm{Vp}$ and $\mathrm{Vs}$ values are moderate and $\mathrm{Vp} / \mathrm{Vs}$ ratio range from 1.76 to 1.80 (See Figures S24 to S32 for checkerboards, ray coverage resolution and restitution index tests respectively).

\section{Discussion}

Based on the seismicity distribution, clusters of similar events, NVTs activity and the velocity anomalies obtained from our $\mathrm{Vp}$ and $\mathrm{Vs}$ models, and $\mathrm{Vp} / \mathrm{Vs}$ ratio (Figures $2 \mathrm{~b}$ and 3) we infered a clear and marked picture of down-dip heterogeneity of the plate interface. From 20 to $35 \mathrm{~km}$ depths (zone A in Figure 4), interplate seismicity is concentrated in clusters up to a depth of approximately $32 \mathrm{~km}$, coinciding precisely with high coupling values reported by geodetic studies (coupling > 0.7, Figure S1). Intraslab seismicity 
233 presents some clusters potentially related to the re-activation of faults in the oceanic crust and also tends to 234 form a seismicity plane towards the bottom of the oceanic crust. Clusters of similar events were identified in 235 this zone at depths from 18 to $29 \mathrm{~km}$ (Figure 2b), close to the seismic swarms (Figures 1 and 2a) and in a 236 zone with low coupling values (Figure S1).

237 Similar and repeating events inside seismic swarms have been observed in the past (Tréhu et al., 2015; Poli 238 et al., 2017; Pastén-Araya et al., 2018, Valenzuela-Malebrán et al., 2021). Several studies have proposed that 239 these events might be caused by heterogeneities in the subduction zone due to the subduction of bathymetric 240 features such as: (1) seamounts associated with oceanic ridges (Bilek and Lay, 2018; Valenzuela-Malebrán et 241 al., 2021) and (2) more local structures like fractured zones, which are capable of transporting a greater 242 quantity of fluids to the interface (Moreno et al., 2014; Poli et al., 2017). In this zone A, the Vp and Vs values are moderate and the $\mathrm{Vp} / \mathrm{Vs}$ ratio is high, with values between 1.78 to 1.82 (Figure 3) suggesting the presence of fluids. According to Nishikawa and Ide (2018), fluid-rich zones are prone to exhibit aseismic slip and host seismic swarms with clusters of similar and repeating events. Therefore, our observations suggest that in zone A there are zones with different seismic behavior: zones with seismic slip characterized by elevated rates of ordinary seismicity with high coupling values (coupling >0.6) (Figure S1) and zones with aseismic slip, characterized by low coupling (coupling < 0.5) (Figure S1), low seismicity rate, clusters of similar events, greater presence of fluids and regular seismic swarms (Figure 4). Subduction of seamounts or oceanic ridges can produce fracturing in the oceanic and upper crust and changes in frictional sliding or ductile deformation at the interface (Wang and Bilek, 2014). Between 20 and $35 \mathrm{~km}$ depths, clusters of similar events and swarms are spatially correlated with the subduction path of the CoR (Figures 1 and 2a). In addition, these similar events are located in less coupled zones (Figure S1). Mochizuki et al. (2008) and recently Chesley et al. (2021) established the subduction of seamounts, with their different geometries, widths and altitudes can influence that the distribution of seismicity, produce low coupling above these structures and can trigger clustered repeating earthquakes and similar events. Plata-Martinez et al. (2021) related the distribution of slow earthquakes in the Mexico subduction zone to the difference in relief produced by the subduction of seamounts. Therefore, we propose that the geometric heterogeneities of the seamounts of CoR could influence the diverse seismic behaviors observed in this zone.

In zone B or transition zone (Figure 4), ordinary interplate seismicity is scarce, and NVTs activity is detected (Figures $2 \mathrm{a}$ and $2 \mathrm{~b}$ ). This boundary between interplate seismicity and the zone where the NVTs occurs is characterized as a transition between a zone of high coupling, unstable and rate-weakening friction and a zone of low coupling, stable and rate-strengthening friction (Figure S1) (Im et al., 2020). Under the assumption that zones hosting slow slip phenomena such as NVTs and SSEs may impede the propagation of seismic ruptures (Rolandone et al., 2018; Nishikawa et al., 2019), this boundary permits a rough estimation of the along-dip extent of potential future subduction earthquake ruptures that can be nucleated in the locked seismogenic zone. The low values of $\mathrm{Vp}$ and $\mathrm{Vs}$ and values of $\mathrm{Vp} / \mathrm{Vs}$ ratio between 1.78 and 1.80 (Figure 3) indicate the presence of fluids in this zone and low normal stress, both factors favor the presence of NVTs 
(Shelly et al., 2006). Nishikawa et al. (2019) recognized NVTs activity in the southern segment of the Japan subduction zone associated to the subduction of seamounts. NVTs activity is mainly located updip of SSE and a little in zone A, similar to what has been observed recently in the Mexico subduction zone (PlataMartinez et al., 2021). Moreover, NVTs activity is spatially correlated with CoR subduction (Figures 2a). Therefore we do not discard that the subduction of the CoR seamounts could affect the frictional properties in the zone hosting the NVTs activity.

Between 42 and $60 \mathrm{~km}$ depth (zone C in Figure 4), both Vp and Vs models potentially represent a large doming structure anomaly in the plate interface and in the oceanic crust (Figure 3). This anomaly presents low $\mathrm{Vp}$ and $\mathrm{Vs}$ velocities and a Vp/Vs ratio between 1.76 and 1.78. Kato et al. (2010) recognized an anomaly with similar characteristics with low velocities in the Japan subduction zone, which they attributed to the subduction of an oceanic ridge. Therefore, we tentatively attribute this anomaly to the subduction of a large seamount associated with the CoR. This anomaly coincides precisely, along-strike and down-dip, with the slip of the SSE (Figure S33a-S33b) and a notable lack of interplate seismicity (Figures 3 and 4). The low Vp and $\mathrm{Vs}$ velocities and $\mathrm{Vp} / \mathrm{Vs}$ ratio suggest the presence of fluids, which could be brought through the ridge and released at these depths (Chesley et al., 2021). This idea is consistent with our observations, as fluid abundance is one of the possible causes of aseismic slip (Bürgmann, 2018; Nishikawa and Ide, 2018). These observations propose a change in the rheology of this zone, promoting an aseismic slip behavior at the interface without seismicity. Temperature variation could be another factor in the lack of interplate seismicity. Some studies suggest an increase in temperature due to crustal thickening caused by subduction of ocean ridges (Tsuru et al., 2002; Kato et al., 2010; Wang and Bilek, 2014). This increase in temperature would produce ductile deformation, which could also explain the lack of interplate seismicity.

Finally, the zone between 60 and $110 \mathrm{~km}$ depth (zone D in Figure 4) corresponds to the zone below the mantle wedge with stable sliding. There is a increase of the $\mathrm{Vp}$ and $\mathrm{Vs}$ velocities and the $\mathrm{Vp} / \mathrm{Vs}$ ratio and a drastic increase of intraslab seismicity. We interpret this increase in seismicity as the onset of the eclogitization metamorphic reaction, due to the dehydration of hydrated minerals in the basaltic oceanic crust and serpentinized upper oceanic mantle (Ferrand et al., 2017; Calvert et al., 2020; Behr and Rürgmann, 2021). The fluids released by the eclogitization could migrate into the mantle wedge enhancing serpentinization in that zone (Hyndman and Peacock, 2003). Our Vp/Vs ratio values $\sim 1.80$ (Figure 3) and absolute velocity values of $\mathrm{Vp} \sim 7.2 \mathrm{~km} / \mathrm{s}$ and $\mathrm{Vs} \sim 4.0 \mathrm{~km} / \mathrm{s}$ (Figure S34) support this interpretation.

\section{Conclusion}

Through seismicity analysis and a 3-D tomography model, we studied the along-dip influence of the CoR subduction in the Atacama region, North-Central Chile. The observed distribution of seismicity, the occurrence of clusters of similar events, NVTs and the Vp, Vs and Vp/Vs ratio anomalies allowed us to identify diverse behaviors with different zones along-dip hosting seismic and aseismic slip (Figure 4). These 
observations are spatially related with the subduction of the Copiapó ridge, a process that could promote along-strike and along-dip changes and favor different slip behavior. Our results present novel observations shedding light on how subduction of large bathymetric features can influence the distribution of seismicity, aseismic slip and the likely extent of along-dip megathrust seismic ruptures in the North-Central Chilean subduction zone.

\section{Acknowledgments}

313 This work is funded by the Fondecyt project $\mathrm{N}^{\circ} 1200779$ and by the Programa de Riesgo Sísmico (PRS), 314 Universidad de Chile. This work has also received funding from the Agence Nationale de la Recherche 315 (projects ANR-19-CE31-0003) and the European Research Council (ERC, under the European Union's 316 Horizon 2020 research and innovation programme under grant agreement No. 805256). F.P-A grateful to 317 Marcos Aros and Daniela Calle-Gardella for their help in the field work and to Emilie Klein, Javier Ojeda and Nicole Krumm for their help during the preparation of this manuscript. L.C was supported by the European Union Horizon 2020 Research and Innovation Programme (grant agreement, 802777MONIFAULTS). Finally, we thank the editor Dr German Prieto and the reviewers A.M. Tréhu and anonymous for their constructive comments to improve the manuscript.

\section{Data Availability Statement} The seismological catalog, station information, travel time data used to make the tomography model and information for searching and locating the NVTs can be obtained from the following repository: https://doi.org/10.34691/FK2/91GHJE (Pastén-Araya, 2021: “Copiapó_ Experiment_Data”). Data obtained from Centro Sismológico Nacional (CSN) are directly available at http://www.sismologia.cl. Data from the Strasbourg University stations (Zigone et al., 2019) can be downloaded from the International Federation Of Digital Seismograph Networks (FDSN). Figures were made using Generic Mapping Tool (GMT) (Wessel et al., 2013) and other open access software.

\section{References}

342 Baba, S., Takemura, S., Obara, K., \& Noda, A. (2020). Slow earthquakes illuminating interplate coupling heterogeneities in subduction zones. Geophysical Research Letters, 47(14), e2020GL088089. 
Bassett, D., \& Watts, A. B. (2015a). Gravity anomalies, crustal structure, and seismicity at subduction zones:

Bassett, D., \& Watts, A. B. (2015b). Gravity anomalies, crustal structure, and seismicity at subduction zones:

2. Interrelationships between fore-arc structure and seismogenic behavior. Geochemistry, Geophysics, Geosystems, 16(5), 1541-1576.

Bassett, D., Sandwell, D. T., Fialko, Y., \& Watts, A. B. (2016). Upper-plate controls on co-seismic slip in the 2011 magnitude 9.0 Tohoku-oki earthquake. Nature, 531(7592), 92-96.

Beck, S., Barrientos, S., Kausel, E., \& Reyes, M. (1998). Source characteristics of historic earthquakes along the central Chile subduction Askew et Alzone. Journal of South American Earth Sciences, 11(2), 115-129.

Behr, W. M., \& Bürgmann, R. (2021). What's down there? The structures, materials and environment of deep-seated slow slip and tremor. Philosophical Transactions of the Royal Society A, 379(2193), 20200218.

Bilek, S. L., \& Lay, T. (2018). Subduction zone megathrust earthquakes. Geosphere, 14(4), 1468-1500.

Bloch, W., Kummerow, J., Salazar, P., Wigger, P., \& Shapiro, S. A. (2014). High-resolution image of the North Chilean subduction zone: seismicity, reflectivity and fluids. Geophysical Journal International, 197(3), 1744-1749.

Bürgmann, R. (2018). The geophysics, geology and mechanics of slow fault slip. Earth and Planetary Science Letters, 495, 112-134.

Calvert, A. J., Bostock, M. G., Savard, G., \& Unsworth, M. J. (2020). Cascadia low frequency earthquakes at the base of an overpressured subduction shear zone. Nature communications, 11(1), 1-10.

Chesley, C., Naif, S., Key, K., \& Bassett, D. (2021). Fluid-rich subducting topography generates anomalous forearc porosity. Nature, 595(7866), 255-260. double-layered seismic zone in Arica, northern Chile. Geophysical Research Letters, 26(13), 1965-1968. 
Comte, D., Haessler, H., Dorbath, L., Pardo, M., Monfret, T., Lavenu, A., ... \& Hello, Y. (2002). Seismicity and stress distribution in the Copiapo, northern Chile subduction zone using combined on-and off-shore seismic observations. Physics of the earth and planetary interiors, 132(1-3), 197-217.

Comte, D., Tassara, A., Farias, M., \& Boroschek, R. (2006, December). 2006 Copiapo Chile seismic swarm analysis: mapping the interplate contact. In AGU Fall Meeting Abstracts (Vol. 2006, pp. S53B-1327).

Contreras-Reyes, E., \& Carrizo, D. (2011). Control of high oceanic features and subduction channel on earthquake ruptures along the Chile-Peru subduction zone. Physics of the Earth and Planetary Interiors, 186(1-2), 49-58.

Ferrand, T. P., Hilairet, N., Incel, S., Deldicque, D., Labrousse, L., Gasc, J., ... \& Schubnel, A. (2017). Dehydration-driven stress transfer triggers intermediate-depth earthquakes. Nature communications, 8(1), 111.

Gibbons, S. J., \& Ringdal, F. (2006). The detection of low magnitude seismic events using array-based waveform correlation. Geophysical Journal International, 165(1), 149-166.

Havskov, J., \& Ottemöller, L. (2008). SEISAN: the earthquake analysis software for windows, solares, linux and macosx, version 8.2. 1. Institute of Solid Earth Science, University of Bergen, Norway.

Hayes, G. P., Moore, G. L., Portner, D. E., Hearne, M., Flamme, H., Furtney, M., \& Smoczyk, G. M. (2018). Slab2, a comprehensive subduction zone geometry model. Science, 362(6410), 58-61.

Henstock, T. J., McNeill, L. C., Bull, J. M., Cook, B. J., Gulick, S. P., Austin Jr, J. A., ... \& Djajadihardja, Y. S. (2016). Downgoing plate topography stopped rupture in the AD 2005 Sumatra earthquake. Geology, 44(1), 71-74.

Holtkamp, S. G., Pritchard, M. E., \& Lohman, R. B. (2011). Earthquake swarms in south america. Geophysical Journal International, 187(1), 128-146.

Ide, S. (2010). Striations, duration, migration and tidal response in deep tremor. Nature, 466(7304), 356-359.

Ide, S. (2012). Variety and spatial heterogeneity of tectonic tremor worldwide. Journal of Geophysical Research: Solid Earth, 117(B3).

Igarashi, T. (2020). Catalog of small repeating earthquakes for the Japanese Islands. Earth, Planets and Space, $72,1-8$. 
416 Im, K., Saffer, D., Marone, C., \& Avouac, J. P. (2020). Slip-rate-dependent friction as a universal 417 mechanism for slow slip events. Nature Geoscience, 13(10), 705-710.

Kanamori, H., Rivera, L., Ye, L., Lay, T., Murotani, S., \& Tsumura, K. (2019). New constraints on the 1922 Atacama, Chile, earthquake from historical seismograms. Geophysical Journal International, 219(1), 645661.

Kato, A., Iidaka, T., Ikuta, R., Yoshida, Y., Katsumata, K., Iwasaki, T., ... \& Hirata, N. (2010). Variations of fluid pressure within the subducting oceanic crust and slow earthquakes. Geophysical Research Letters, $37(14)$.

Klein, E., Metois, M., Meneses, G., Vigny, C., \& Delorme, A. (2018a). Bridging the gap between North and Central Chile: Insight from new GPS data on coupling complexities and the Andean sliver motion. Geophysical Journal International, 213(3), 1924-1933.

Klein, E., Duputel, Z., Zigone, D., Vigny, C., Boy, J. P., Doubre, C., \& Meneses, G. (2018b). Deep transient slow slip detected by survey GPS in the region of Atacama, Chile. Geophysical research letters, 45(22), 12263.

Klein, E., Potin, B., Pasten-Araya, F., Tissandier, R., Azua, K., Duputel, Z., ... \& Vigny, C. (2021). Interplay of seismic and a-seismic deformation during the 2020 sequence of Atacama, Chile. Earth and Planetary Science Letters, 570, 117081.

Kodaira, S., Iidaka, T., Kato, A., Park, J. O., Iwasaki, T., \& Kaneda, Y. (2004). High pore fluid pressure may cause silent slip in the Nankai Trough. Science, 304(5675), 1295-1298.

Lallemand, S., Peyret, M., van Rijsingen, E., Arcay, D., \& Heuret, A. (2018). Roughness characteristics of oceanic seafloor prior to subduction in relation to the seismogenic potential of subduction zones.

444 Geochemistry, Geophysics, Geosystems, 19(7), 2121-2146.

445 Liu, X., \& Zhao, D. (2018). Upper and lower plate controls on the great 2011 Tohoku-oki earthquake. 446 Science advances, 4(6), eaat4396.

448 Maksymowicz, A. (2015). The geometry of the Chilean continental wedge: Tectonic segmentation of 449 subduction processes off Chile. Tectonophysics, 659, 183-196. 
Maksymowicz, A., Ruiz, J., Vera, E., Contreras-Reyes, E., Ruiz, S., Arraigada, C., ... \& Bascuñan, S. (2018). Heterogeneous structure of the Northern Chile marine forearc and its implications for megathrust earthquakes. Geophysical Journal International, 215(2), 1080-1097.

Marot, M., Monfret, T., Pardo, M., Ranalli, G., \& Nolet, G. (2013). A double seismic zone in the subducting 456 Juan Fernandez Ridge of the Nazca Plate (32 S), central Chile. Journal of Geophysical Research: Solid Earth, 118(7), 3462-3475.

Mochizuki, K., Yamada, T., Shinohara, M., Yamanaka, Y., \& Kanazawa, T. (2008). Weak interplate coupling by seamounts and repeating M 7 earthquakes. Science, 321(5893), 1194-1197.

Moreno, M., Haberland, C., Oncken, O., Rietbrock, A., Angiboust, S., \& Heidbach, O. (2014). Locking of 463 the Chile subduction zone controlled by fluid pressure before the 2010 earthquake. Nature Geoscience, 7(4), 292-296.

Nishikawa, T., \& Ide, S. (2018). Recurring slow slip events and earthquake nucleation in the source region of the M 7 Ibaraki-Oki earthquakes revealed by earthquake swarm and foreshock activity. Journal of Geophysical Research: Solid Earth, 123(9), 7950-7968.

Nishikawa, T., Matsuzawa, T., Ohta, K., Uchida, N., Nishimura, T., \& Ide, S. (2019). The slow earthquake spectrum in the Japan Trench illuminated by the S-net seafloor observatories. Science, 365(6455), 808-813. Pastén-Araya, F., Salazar, P., Ruiz, S., Rivera, E., Potin, B., Maksymowicz, A., ... \& Shapiro, S. A. (2018). Fluids along the plate interface influencing the frictional regime of the Chilean subduction zone, northern Chile. Geophysical Research Letters, 45(19), 10-378.

Plata-Martínez, R., Ide, S., Shinohara, M., Garcia, E. S., Mizuno, N., Dominguez, L. A., ... \& Ito, Y. (2021). Shallow slow earthquakes to decipher future catastrophic earthquakes in the Guerrero seismic gap. Nature

Poli, P., Maksymowicz, A., \& Ruiz, S. (2017). The Mw 8.3 Illapel earthquake (Chile): Preseismic and

Potin, B. (2016). Les Alpes occidentales: tomographie, localisation de séismes et topographie du Moho 485 (Doctoral dissertation, Université Grenoble Alpes (ComUE)).

Potin, B., S, Barrientos., B, Vallete and S, Ruiz (2019). Tomography of Chile, in 8th International Symposium on Andean Geodynamics (ISAG). 
Rolandone, F., Nocquet, J. M., Mothes, P. A., Jarrin, P., Vallée, M., Cubas, N., ... \& Font, Y. (2018). Areas prone to slow slip events impede earthquake rupture propagation and promote afterslip. Science advances, 4(1), eaao6596.

Ruiz, S., \& Madariaga, R. (2018). Historical and recent large megathrust earthquakes in Chile. Tectonophysics, 733, 37-56.

Sáez, M., Ruiz, S., Ide, S., \& Sugioka, H. (2019). Shallow nonvolcanic tremor activity and potential repeating earthquakes in the Chile Triple Junction: seismic evidence of the subduction of the active NazcaAntarctic spreading center. Seismological Research Letters, 90(5), 1740-1747.

Shelly, D. R., Beroza, G. C., Ide, S., \& Nakamula, S. (2006). Low-frequency earthquakes in Shikoku, Japan, and their relationship to episodic tremor and slip. Nature, 442(7099), 188-191.

502 Tréhu, A. M., Blakely, R. J., \& Williams, M. C. (2012). Subducted seamounts and recent earthquakes beneath the central Cascadia forearc. Geology, 40(2), 103-106.

Tréhu, A. M., Braunmiller, J., \& Davis, E. (2015). Seismicity of the central Cascadia continental margin near 44.5 N: A decadal view. Seismological Research Letters, 86(3), 819-829.

Tsuru, T., Park, J. O., Miura, S., Kodaira, S., Kido, Y., \& Hayashi, T. (2002). Along-arc structural variation of the plate boundary at the Japan Trench margin: Implication of interplate coupling. Journal of Geophysical Research: Solid Earth, 107(B12), ESE-11.

512 Uchida, N., \& Matsuzawa, T. (2013). Pre-and postseismic slow slip surrounding the 2011 Tohoku-oki 513 earthquake rupture. Earth and Planetary Science Letters, 374, 81-91.

Uchida, N. (2019). Detection of repeating earthquakes and their application in characterizing slow fault slip. Progress in Earth and Planetary Science, 6(1), 1-21.

519 Seismicity clusters in Central Chile: investigating the role of repeating earthquakes and swarms in a subduction region. Geophysical Journal International, 224(3), 2028-2043. 39(9), 819-822. 
525 Wang, K., \& Bilek, S. L. (2014). Invited review paper: Fault creep caused by subduction of rough seafloor

526 relief. Tectonophysics, 610, 1-24.

Zigone, D., Duputel, Z., Rivera, L., Thore, J.Y., Klein, E., Vigny, C \& Ruiz. S (2019). Copiapo temporary deployment, International Federation of Digital Seismograph Networks. Doi.org/10.7914/SN/9C_2019.

\section{Figures captions}

Fig 1. Seismotectonic context. The pink lines and star indicate the historical and recent earthquakes. The green and lightblue triangles correspond to the two phases of the temporary broad-band network. The brown and yellow triangles correspond to semi-permanent broad-band stations of the Strasbourg university and the permanent stations of Centro Sismológico Nacional (CSN) respectively. The white line indicates de CoR and its seamounts. The orange dots indicate the seismic swarm of 2006, and the red lines are slip contours of the 2014 deep SSE, each contour is $50 \mathrm{~mm}$ of slip (Klein et al., 2018b). The segmented black lines correspond to Slab2.0 model (Hayes et al., 2018) and the white triangles indicate the trench.

Fig 2. a) Orange dots correspond to our seismicity catalog, yellow stars to clusters of similar events, and blue stars to NVTs activity. The red lines indicate the 2014 SSE (Klein et al., 2018b). The segmented black lines indicate the seismicity zone in profile A-A'. Segmented blue lines indicate the zone covered by our tomographic profile in Figure 3. b) Seismicity profile between the black segmented lines indicated in a). Clusters of similar events, NVTs and SSE are indicated with the same colors as in a). The black line indicates bathymetry and Slab2.0 (Hayes et al., 2018) with interplate seismicity. The blue segmented line indicates the intermediate plane of intraslab seismicity in the oceanic crust and the red segmented line indicating the lower plane of intraslab seismicity in the upper oceanic mantle. c) Example of similar event detections (in black) and the corresponding templates (in red) and d) Example of NVT obtained with the envelope method.

Fig 3. Cross-section of the 3-D relative tomographic velocity models. a) Vp model, b) Vs model, c) Vp/Vs ratio model. Yellow and blue stars indicate clusters of similar events and NVTs activity respectively. The solid black line indicates Slab2.0 (Hayes et al., 2018), and the solid red line to SSE (Klein et al., 2018b). The blue and red segmented lines indicate seismicity planes (black dots) in the oceanic crust and upper oceanic mantle. The less illuminated areas represent areas with lower resolution.

557 Fig 4. Representation of seismic and aseismic slip zones along-dip in the CoR subduction zone. Interplate 558 and intraslab seismicity (orange dots), clusters of similar events (yellow stars), NVTs (blue stars) and SSE 559 (solid red line). The pink line indicates the potential seamount doming anomaly which coincides with the 560 SSE and without seismicity. The light blue arrows indicate the presence and leakage of fluids. More intense sesimicity between 60 and $110 \mathrm{~km}$ depth indicating possible eclogitization metamorphic reactions. 
Figure 1. 


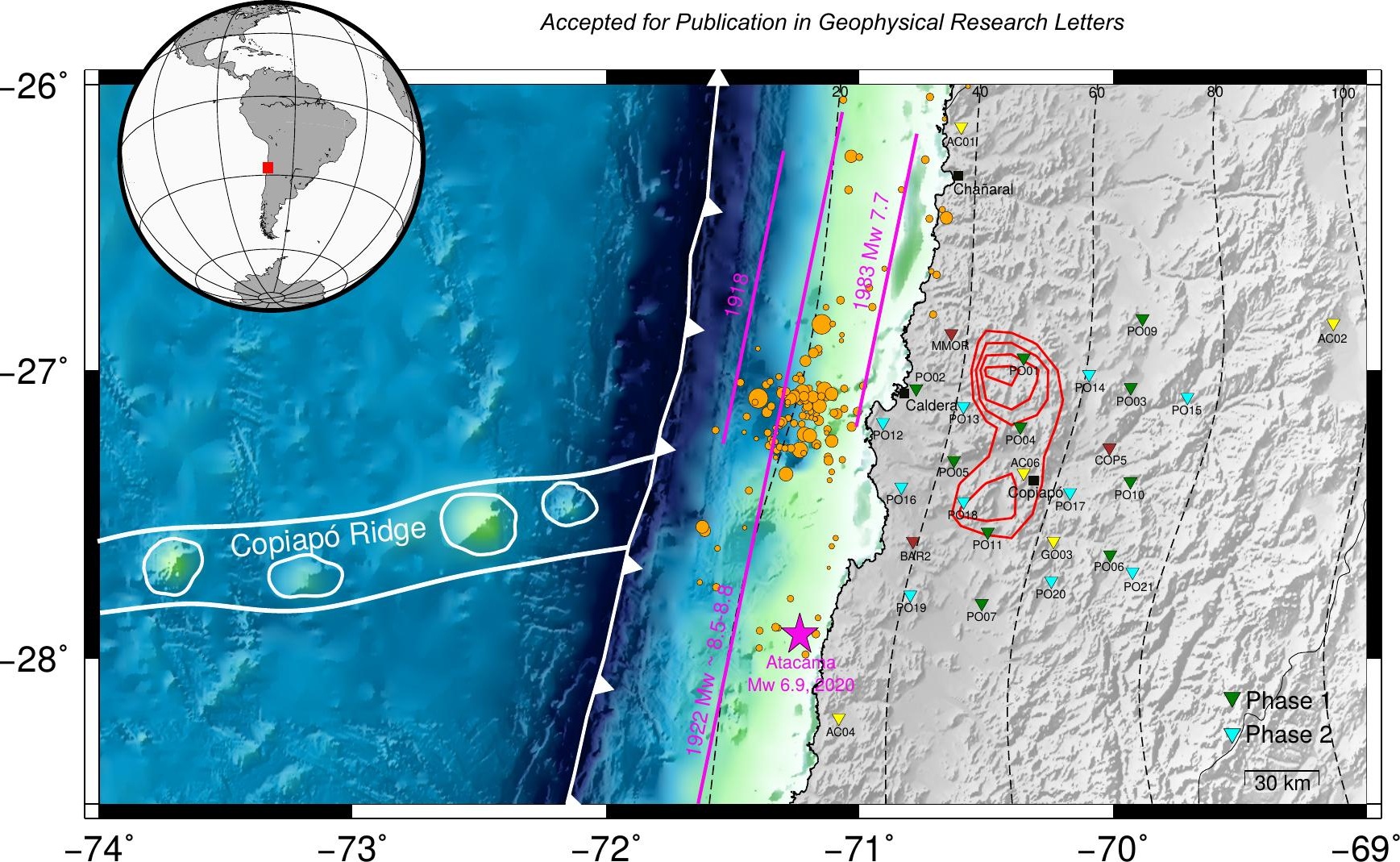


Figure 2. 


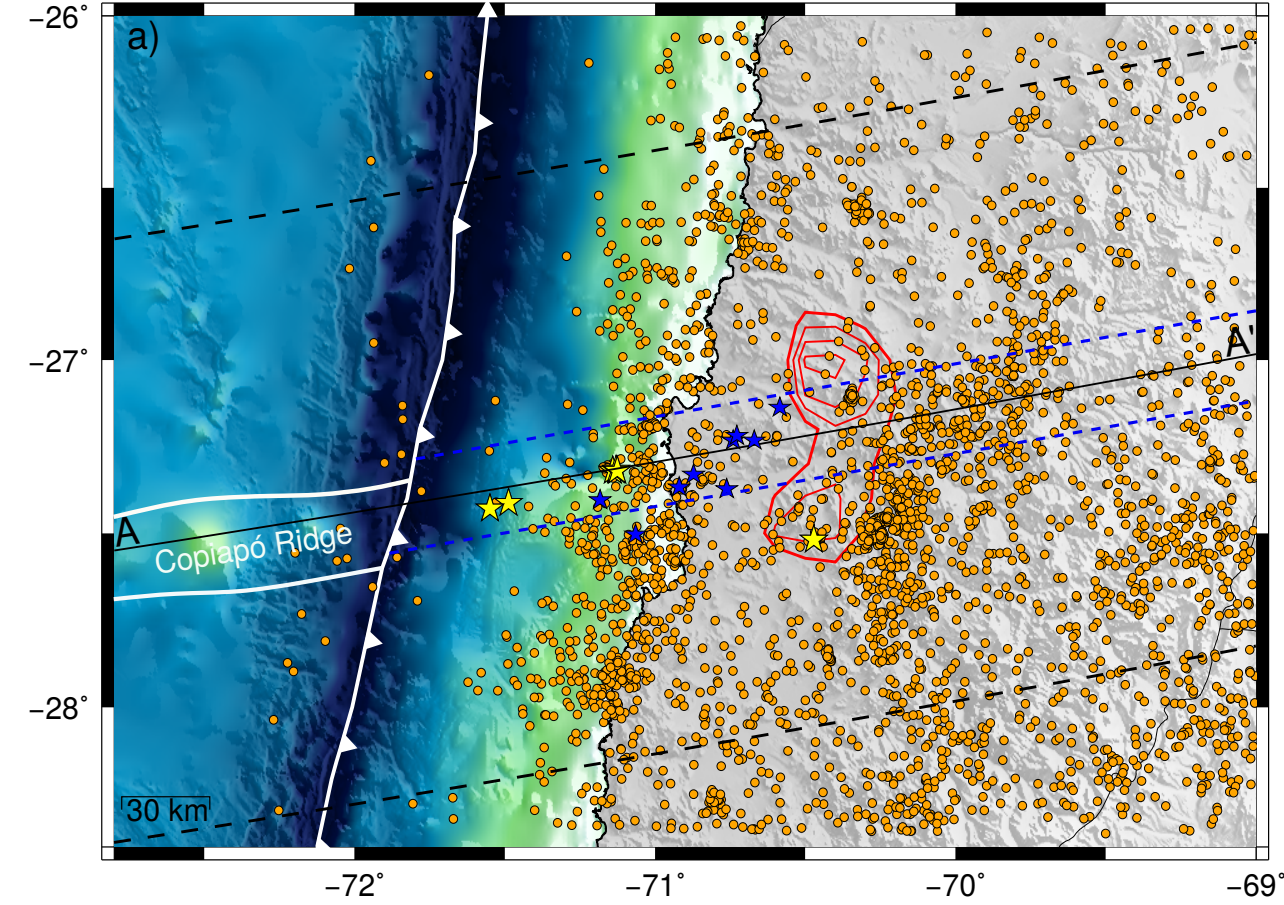

b) Profile A-A'

c)

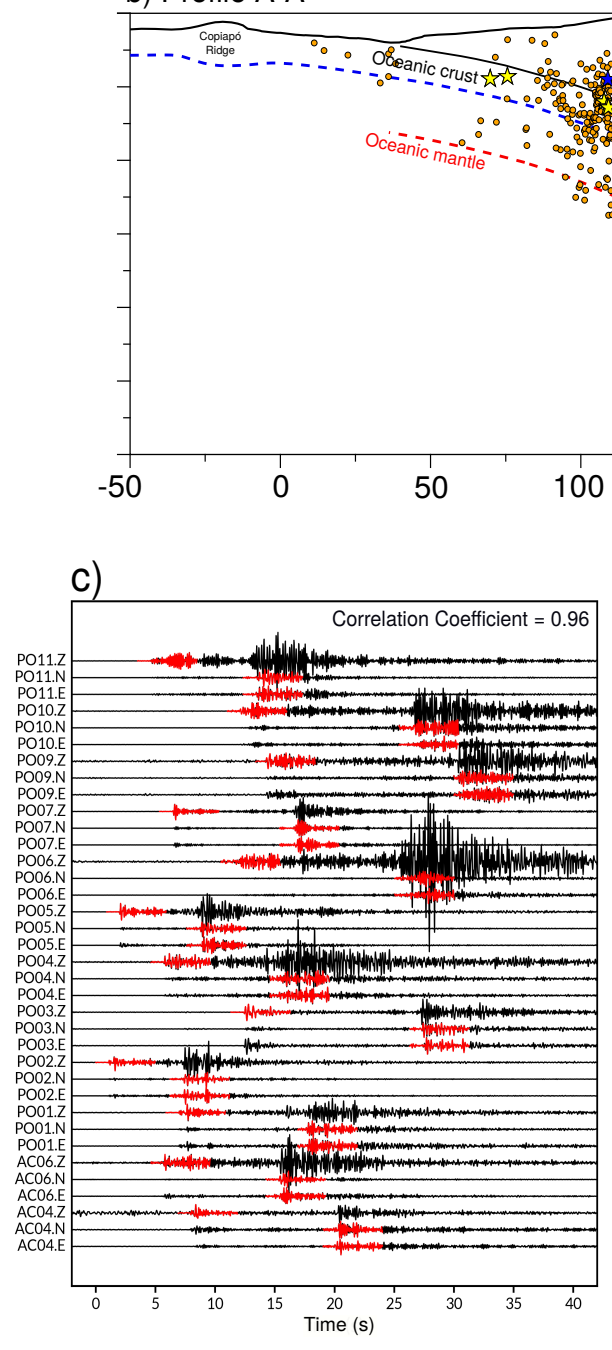

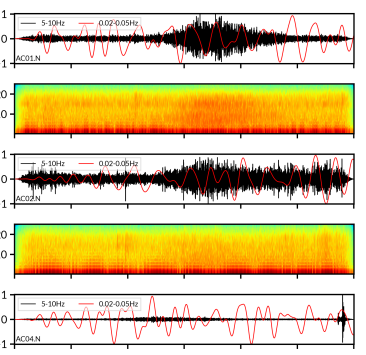

d)
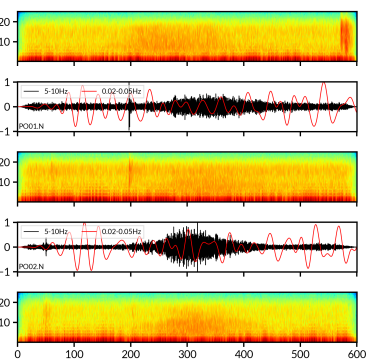

$250 \quad 300$
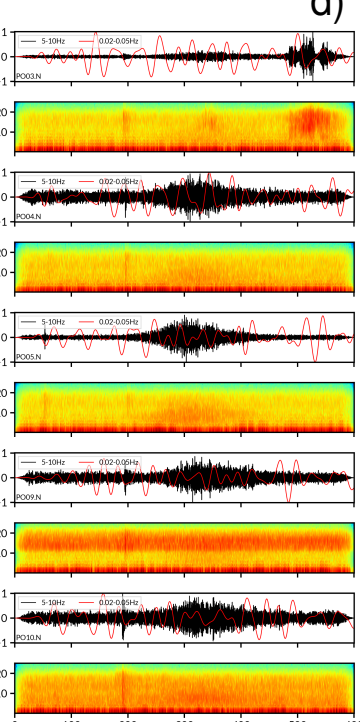
Figure 3. 


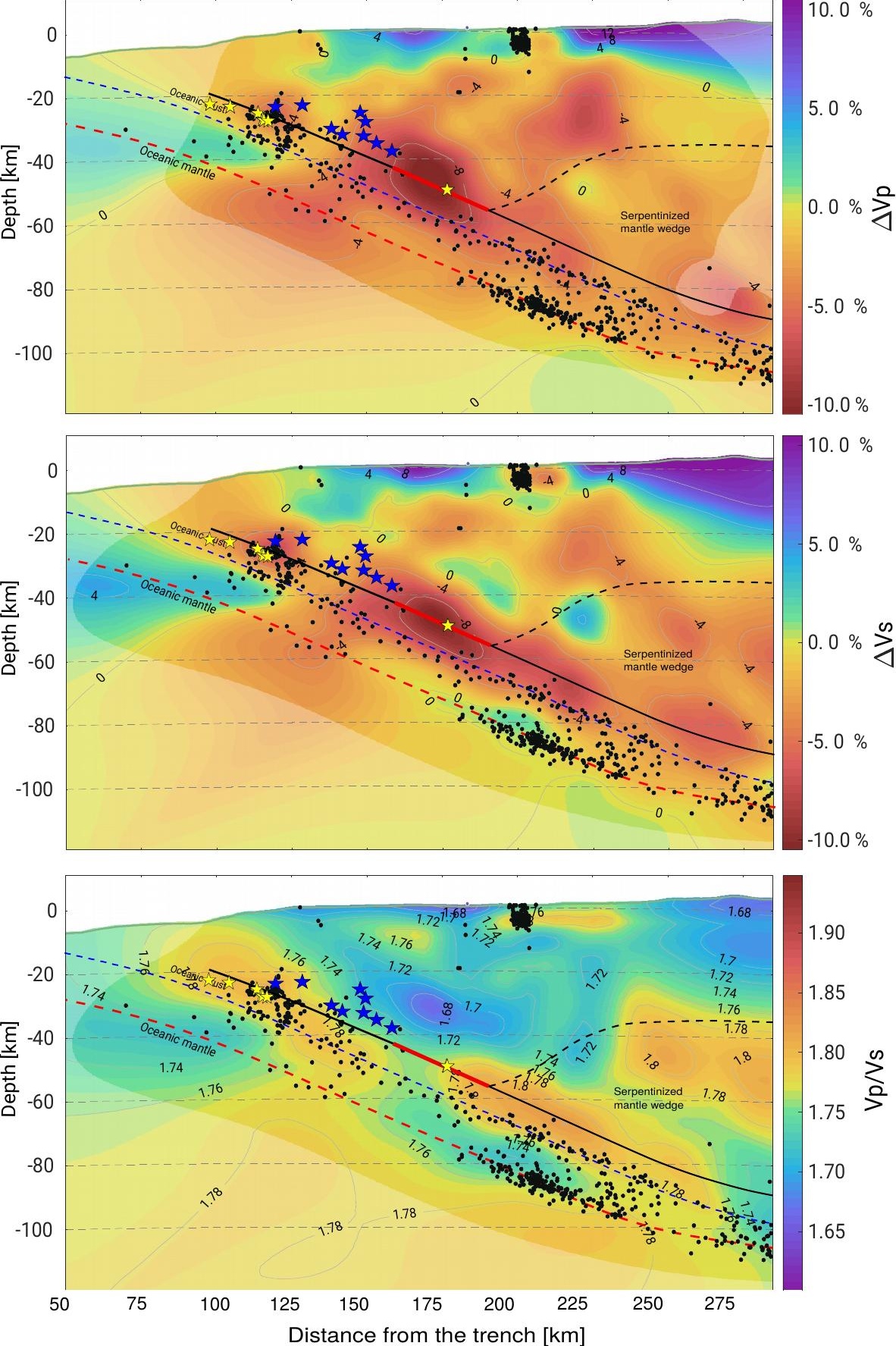


Figure 4. 
